\title{
Diáspora estudantil africana: revisão de literatura
}

\section{African student diaspora: a literature review}

Camila Rodrigues Francisco ${ }^{1}$

Resumo: O objetivo deste artigo é apresentar a revisão de literatura realizada sobre o deslocamento de estudantes de países africanos para o Brasil com fins de estudos, entendida aqui como diáspora estudantil. Foram revisados 35 trabalhos, sendo 28 dissertações de mestrado e 7 teses de doutorado, publicadas entre os anos 2000 e 2017. Além destes dados compilados, foram conjugados os resultados da pesquisa de mestrado que deu origem a esta revisão, apresentando importantes reflexões acerca da chegada destes e destas estudantes no Brasil, os projetos de futuro, questões da permanência atravessadas pela questão racial e de gênero, entre outros aspectos.

Palavras-chave: estudantes universitários; diáspora estudantil; PEC-G; África.

\begin{abstract}
The article aim to present the literature review about the displacement of African countries students to Brasil with study purposes, conceived here as student diaspora. The material reviewed is 29 master researches and 7 doctoral thesis published between 2000 and 20017. Beyond the compiled data, the results of the master's research that started this review were combined presenting important thoughts about the arrival of these students in Brasil, their future projects, the period of stay crossed by the racial and gender issue, among other aspects.
\end{abstract}

Keywords: college students; student diaspora; PEC-G; Africa.

\section{INTRODUÇÃO}

Sair do país de origem em busca de uma qualificação profissional configura um tipo muito específico de deslocamento territorial. A diáspora estudantil, ou a migração com fins de estudos, tem uma abordagem específica na literatura, na realidade e subjetividade das pessoas em trânsito, e também é vista de maneira muito particular pelos organismos internacionais.

\footnotetext{
${ }^{1}$ Mestre em Psicologia pela Universidade Federal de Minas Gerais. E-mail: cfmilarodrigues@gmail.com. ORCID: https://orcid.org/0000-0002-9867-9095.
} 
Apresento, a seguir, um recorte ampliado da revisão de literatura realizada na pesquisa de mestrado, fonte das inquietações e questionamentos que culminaram inclusive na escolha de trabalhar com mulheres haitianas (Francisco, 2019). Para fins deste trabalho, cumpre apenas mencionar que diáspora africana, como entendida aqui, está nas experiências que partem de origens diferentes para um mesmo destino, no nosso caso o Brasil, e neste se materializam o terror racial (Gilroy, 2001), o genocídio anti-negro (Vargas, 2017) ou as lutas e resistências em torno do sistema de opressão racial, que são compartilhadas em distintos destinos ou pontos da diáspora no globo. Em diálogo com pesquisadores africanos (Langa, 2016; Djaló, 2014; Munanga, 2008), diáspora estudantil diz portanto do deslocamento de estudantes de países africanos a diferentes destinos, que pode ser também encontrada na literatura como migração ou mobilidade estudantil.

O Pacto Global da Migração da ONU, realizado em 2018, englobava distintas modalidades de movimentos migratórios, incluindo a mobilidade estudantil (Baeninger, 2018). No Brasil, a Lei no 13.445, mais recente publicação e importante marco histórico brasileiro acerca dos deslocamentos internacionais internos e externos publicada em 2017 (Culpi, 2017; Domenech, 2015), prevê a concessão de vistos temporários para a finalidade de estudos ${ }^{2}$.

Enquanto lido como um fenômeno de pequena magnitude dentro dos diversos tipos de migrações, quando visto como uma estratégia de internacionalização, a mobilidade estudantil é tida como protagonista (Pinto; Larrechea, Castro; Neto, 2012). Tal fenômeno aponta ainda para uma série de ambiguidades, dentre elas a seletividade na imposição de fronteiras, por sua vez diretamente relacionada às relações globalizantes entre a migração internacional estudantil e a qualificação da força de trabalho (Souza, 2014).

\section{O PROGRAMA PEC-G}

Todos os trabalhos aqui identificados vinculam-se parcialmente ou totalmente aos estudantes provenientes do Programa Estudantes Convênio da graduação (PEC-G) e da pós-graduação (PEC-PG), este que é tido como o maior programa de internacionalização do Brasil (Miranda, 2016).

Trata-se de um tratado assinado pelo Brasil com países em desenvolvimento para receber estudantes de graduação e pós-graduação nas instituições de ensino superior brasileiras criado oficialmente em 1964. Ainda que tenha sido criado em um contexto de grande fluxo de estudantes internacionais para o Brasil, só deixou de ser restrito aos estudantes latino-americanos em 1974. Teve um breve período de gestão feita pela CAPES,

\footnotetext{
${ }^{2}$ A concessão dos vistos, documentos que possibilitam ao estrangeiro o ingresso no território nacional brasileiro, conforme consta da lei, são: 1) visita; 2) temporário; 3) diplomático; 4) oficial; 5) de cortesia (Brasil, 2017). No visto temporário, onde se encontra a acolhida humanitária e o visto com fim de estudos ou finalidade de pesquisa, ensino ou extensão acadêmica, a questão da atividade remunerada é regulamentada individualmente. Os e as estudantes estrangeiros do acordo aqui enfatizado [ver PEC-G na próxima seção] encontram-se nesta categoria de visto temporário para estudos, e neste caso, não é permitida a execução de atividade remunerada.
} 
mas é gerido atualmente pelo Ministério de Relações Exteriores, instituição que o criou, junto ao governo dos países concordantes (Amaral, 2013).

Importa mencionar que alguns trabalhos aqui revisados tem como problema de pesquisa o próprio programa PEC-G (Amaral, 2013; Feijó, 2013), apresentando-o como uma política de ação afirmativa (Có, 2011); outro dedica-se a contextualizar as relações históricas Sul-Sul (Djaló, 2014). De maneira mais específica, uma pesquisa aborda o Promisaes - a bolsa do Projeto Milton Santos de acesso ao Ensino Superior, oferecida pelo Ministério da Educação (MEC) desde 2006 - como uma política de assistência estudantil (Batista, 2015) e o exame Celpe-Bras (Bizon, 2013).

Notas metodológicas

Minha inserção no campo bibliográfico da pesquisa se deu a partir de uma busca pelas produções acadêmicas acerca da experiência de estudantes estrangeiros negros no Brasil. Ela foi realizada inicialmente por meio de uma busca no banco de dissertações e teses da CAPES com as palavras-chave "estudantes estrangeiros", que apresentou resultados que envolvem pesquisas sobre o acolhimento dos mesmos no país. A maioria falava de estudantes intercambistas, e não se falava sobre a cor ou raça destes estudantes, pois a identificação se centrava na nacionalidade. Com os termos “estudantes negros" temos vários resultados relacionados à política de ações afirmativas das universidades brasileiras.

Portanto, a escolha final foi por "estudantes africanos", na qual os resultados se relacionavam diretamente ao objetivo desta pesquisa, adotando os seguintes critérios: 1) pesquisas que tratem de estudantes de nível universitário, que vieram cursar a graduação de forma integral no país; 2) pesquisas racializadas, ou seja, onde os relatos dos estudantes ou o referencial teórico mencione as questões raciais no Brasil.

A busca tinha sido iniciada a partir de artigos que, inclusive, levavam às pesquisas mais completas. Sendo assim, optei por centrar esta busca diretamente nas teses e dissertações. Foram adicionados ainda textos que eram citados por mais de um trabalho revisado, em diálogo com os critérios previamente adotados. A revisão aqui apresentada foi feita utilizando 35 trabalhos, sendo 28 dissertações de mestrado e 7 teses de doutorado. Tais estudos foram publicados entre os anos de 2000 a 2017, sendo no ano de 2015 publicados oito trabalhos, seis em 2013 e quatro em 2016.

No que se refere à área de vinculação dos programas de pós-graduação nos quais foram realizados, foram encontradas nove pesquisas na área da Antropologia (Santos, 2012; Tcham, 2012; Có, 2011; Feijó, 2013; Mendes, 2012; Mungoi, 2006; Ngomane, 2010; Okawati, 2015; Pedro, 2000); seis na área da Educação (Assunção, 2015; Batista, 2015; Filgueira, 2014; Gomes, 2002; Rodrigues, 2013; Silva, 2015), cinco na Psicologia (Carvalho, 2016; Girardi, 2015; Mendonça, 2017; Figueiredo, 2013; Alves, 2008); quatro no campo da Sociologia (Cabral, 2015; Langa, 2016; Mourão, 2003; Djaló, 2014) e dois nas Ciências Sociais (Hirsch, 2007; Mourão, 2013), sendo 27 trabalhos de outras áreas.

Tais trabalhos estão vinculados a 31 diferentes programas de pós-graduação brasileiros, com maior número de produções advindas da Universidade de Brasília (Mendes, 2012; Amaral, 2013; Rodrigues, 2013; Batista, 2015) e da Universidade Federal de Santa 
Catarina (Pedro, 2000; Djaló, 2014; Girardi, 2015; Okawati, 2015), que possuem quatro trabalhos cada; a Universidade Federal do Rio Grande do Sul (Mungoi, 2006; Feijó, 2013; Cabral, 2015) e a Universidade Federal do Ceará (Langa, 2016; Mourão, 2006; Mendonça, 2017) com três; e a Universidade do Estado do Rio de Janeiro (Mourão, 2013; Alves, 2008) e a Universidade Federal de Minas Gerais com dois (Ngomane, 2010; Gomes, 2002). Um estudo da Universidade Lusófona de Humanidades e Tecnologias de Lisboa que apareceu na base de dados foi incluído por se aproximar dos critérios estabelecidos para esta pesquisa (Filgueira, 2014).

No que se refere ao campo metodológico, localizam-se pesquisas qualitativas e pesquisas que se utilizam de métodos mistos ou definidas como quanti-quali, não tendo estudos exclusivamente quantitativos. Em todos os estudos, aparecem os e as estudantes como participantes ou interlocutores da pesquisa, agregando-se também pessoas envolvidas institucionalmente com os programas de internacionalização (como professores, gestores, entre outros). A etnografia aparece como método utilizado não só pelas pesquisas na Antropologia, mas também na Sociologia, Ciências Sociais e Políticas Públicas; as entrevistas prevalecem como a técnica mais utilizada, seguida da observação participante, pesquisa documental ou bibliográfica, em documentos oficiais e dados dos sites das próprias universidades, do Ministério de Relações Exteriores (MRE), entre outras páginas oficiais. Ainda que a etnografia e a observação participante tenha envolvido a participação em eventos coletivos, apenas um estudo se utilizou de uma técnica grupal - grupos de discussão - para coleta de dados, no campo da Educação (Rodrigues, 2013). Duas pesquisas mencionam o uso de questionários, combinado com outras técnicas de coleta de dados.

Nos trabalhos revisados, alguns se concentram em uma mesma nacionalidade, em especial, Angola (Gomes, 2002), Cabo Verde (Alves, 2008; Mourão, 2013; Bento, 2005; Hirsch, 2007), Guiné-Bissau (Có, 2011; Djaló, 2014), Moçambique (Ngomane, 2010) e República Democrática do Congo (Bizon, 2013; Santos, 2012). Sete estudos abordam estudantes dos Países Africanos de Língua Oficial Portuguesa (Palop) - a saber, Angola, Cabo Verde, Guiné-Bissau, Moçambique e São Tomé e Príncipe (Tcham, 2012; Silva, 2015; Souza, 2014; Carvalho, 2016; Amaral, 2013; Sousa, 2015; Mendonça, 2017; Rodrigues, 2013). Aparecem ainda, junto a estes, estudantes do Benin, Camarões, Congo-Brazzaville, Costa do Marfim, Gana, Guiné-Equatorial, Egito, Nigéria e Senegal; e quando o marco da pesquisa eram estudantes estrangeiros no geral, aparecem outros países como Colômbia, Cuba, Haiti, Honduras, Jamaica, Panamá, Paraguai, Peru.

Importante destacar ainda aqueles e aquelas que se localizam em sua pesquisa, como "estrangeiros pesquisando a si mesmos", ou seja, estudantes de países africanos que pesquisaram a própria condição de diáspora em que se encontravam: Anso da Silva (2015), João Có (2011) e Mamadú Djaló (2014), Ismael Tcham (2012) da Guiné-Bissau; Maria de Fátima Alves (2008), de Cabo Verde; Dulce Mungoi (2006), Ercílio Langa, (2016) e Yara Neusa Ngomane (2010), de Moçambique; José Manuel Sita Gomes (2002) e Verônica Pedro (2000), de Angola. Quanto aos pesquisadores de nacionalidade brasileira, apenas Edilma Desidério (2006) se identifica como afrodescendente. 
Embora a proposta dos estudos seja delimitada de forma muito diversificada entre si, três grandes temas emergem a partir do objetivo geral identificado pelos seus autores e autoras $^{3}$ : 1) a questão da identidade (Alves, 2008; Bento, 2005; Djaló, 2014; Hirsch, 2007; Langa, 2014; Mourão, 2003; Mungoi, 2004; Ngomane, 2010; Pedro, 2000; Tcham, 2012); 2) a questão da imigração (Desiderio, 2006; Ferreira, 2017; Girardi, 2017; Okawati, 2015; Rodrigues, 2013; A. Silva, 2015; Souza, 2014); 3) a própria experiência dos estudantes no Brasil (Assunção, 2015; Figueiredo, 2013; Lourenço, 2016; A.G.S. Silva, 2015; Có, 2011; Gomes, 2002; Ngomane, 2010; Sousa, 2015; Filgueira, 2014; Mourão, 2013). Além dos que estudam o programa PEC-G que serão mencionados a seguir, os demais trabalhos abordam questões como o projeto destes estudantes (Carvalho, 2016; Mourão, 2013; Santos, 2012), o consumo de telenovelas brasileiras (Mendes, 2012) e o preconceito e o racismo no Brasil (Mendonça, 2017).

Emergência dos relatos

Mencionarei a seguir alguns pontos de consenso ${ }^{4}$ entre os autores e autoras, ou seja, blocos temáticos que convergem a partir dos relatos dos e das interlocutoras das pesquisas aqui revisadas.

Um primeiro bloco que destaco são os problemas que os estudantes enfrentam na chegada ao Brasil. Eles se encontram principalmente confrontados pelas dificuldades com a produção da documentação, pela ausência de algum tipo de recepção ou acolhimento efetivo, pela busca por moradia (Lourenço, 2016), pelas questões da língua, motivo por serem subestimados por colegas de classe ou por professores (Mungoi, 2006), pelas dificuldades na prova de proficiência em língua portuguesa, e pelas diferenças ou dificuldades de reconhecimento na escrita e na fala no caso de estudantes de origem em países lusófonos (Gomes, 2002).

Outro ponto importante que emerge são as redes que tais estudantes estabelecem entre si, seja tendo como critério aproximações com relação à língua e ao continente, mas, sobretudo, com o país de origem. Fica evidente em alguns dos trabalhos a importância destas redes de conexões entre os e as colegas, familiares e amigos para uma experiência de chegada mais integradora e como ponto positivo durante a permanência (Hirsh, 2007; Langa, 2016). Uma das formas encontradas pelas comunidades diaspóricas para lidar com o estado ora de exclusão ora de integração na sociedade anfitriã é o estabelecimento de redes de relações e negociações para assegurar sua existência e sobrevivência (Tambiah, 2000). A conformação destas redes remonta a uma experiência positiva pois

\footnotetext{
${ }^{3}$ Para esta categoria, foi utilizada exclusivamente a leitura do que os autores e autoras identificaram como objetivo geral ou principal da pesquisa, normalmente localizado na introdução ou no capítulo metodológico. A fim de agrupá-los, algumas aproximações generalizantes foram assumidas por esta pesquisadora, como por exemplo, o estudo que mencionava como objetivo estudar as trajetórias de estudantes foi abarcado dentro do bloco 3, experiências; na questão da imigração, identidade e projeto aparecem distintas qualificações.

${ }^{4}$ Foi adotado como consenso a convergência das categorias mencionadas nos relatos da literatura selecionada. Salvo as particularidades dos mesmos, trata-se de pontos que aparecem na maioria das pesquisas, se não em todas. Por isso, foram destacados apenas alguns dos trabalhos abordados.
} 
agrega assistência e apoio ao recém-chegado(a) que ainda não entende como funcionam as regras deste novo local (Francisco, 2019).

O terceiro ponto que ressalto são os jogos de identificação que oscilam entre afirmar cotidianamente, seja pelas interpelações externas, seja por motivações próprias, as diferenças entre países da África, a diversidade existente em cada território e afirmar-se genericamente como africano ou como estudante estrangeiro (Có, 2011). O caso cabo-verdiano aponta para uma tensão importante nesse sentido (Alves, 2008). Parece também ter algo a ver com uma diferenciação do negro brasileiro, ou mesmo de outras nacionalidades, que são agrupadas como africanos pela questão racial fenotípica (como é o caso do Haiti, República Dominicana, Colômbia, entre outros). Nesse sentido, em ambas hipóteses podemos identificar uma estratégia de enfrentamento ao racismo da sociedade brasileira ou àquilo que emerge dos estereótipos vinculados à África.

As pesquisadoras Thula Pires, Vanessa Berner e Julia França falam em uma "linha de raciocínio ambivalente" (Pires, Berner \& França, 2016: p. 796) que ajudaria a explicar este ponto. Há uma série de diferenças entre os diferentes países da África, que inclusive impossibilitam a união destes e destas estudantes em torno de uma "comunidade africana" absoluta (Langa, 2016). Por outro lado, diante de situações de opressão ou de uma necessidade de diferenciação dos brasileiros e brasileiras (que podem ocorrer ao mesmo tempo), mobiliza-se ou apresenta-se de maneira mais explícita a "africanidade", que inclusive pode ser a primeira interpelação de união ou identificação nessa direção (Okawati, 2015).

Vale ressaltar ainda que, ao partir da identificação enquanto estrangeiro ou estrangeira, e mais precisamente enquanto africano ou africana, tais estudantes ficam sujeitos a um outro tipo de essencialização ou inferiorização. Ou seja, estão expostos ao racismo por serem negros e negras -a questão fenotípica da negritude é uma característica que na sociedade brasileira coloca as pessoas em uma situação de desigualdade e de opressão - e então quando se identificam como estrangeiros e estrangeiras, passam por um outro tipo de interpelação opressora, do lugar do desconhecimento e inferiorização atribuindo atrasos à cultura (Mendonça, 2017).

Isso tem a ver inclusive com o que é veiculado midiaticamente sobre a África no Brasil. Pensando nas imagens que circulam externamente, também aparece a diferença entre o Brasil da mídia, com destaque às telenovelas e aos programas de notícia populares nos países da África, onde o Brasil é visto (ou vendido) como paraíso terrestre por suas paisagens, pela imagem das mulheres brasileiras, ao mesmo tempo em que aparece como local de intensa violência urbana e um país de diversões (Alves, 2008; Silva, 2015; Mendes, 2012; Mendonça, 2017; Mourao, 2013).

Importa mencionar ainda o questionamento sobre o futuro dos/das estudantes e a possibilidade de regresso aos respectivos países de origem. Além de evocar as motivações e projeções que trouxeram eles e elas até o Brasil, tal questionamento carrega consigo contradições, e, a seguir, apontaremos uma delas.

Ainda que o futuro de tais estudantes esteja previsto pelo programa através da obri- 
gação de retornar ao país ao fim do curso e muitos desejem isso (Alves, 2008), os e as estudantes costumam traçar planos para os próximos passos, que incluem a permanência no país por mais tempo para maior qualificação. Há, porém, muita incerteza nestes planos (Mendonça, 2017). Eles estão sujeitos a acordos acadêmicos, à disponibilidade de bolsas, à aprovação em um novo processo seletivo, entre outros tantos aspectos que geram inclusive o deslocamento em direção a outros países com mais oportunidades; tais estudantes, portanto, parecem sempre ser "convidados/as ao retorno" (Souza, 2014: p. 111). Demonstrou-se uma relação das projeções do futuro com as motivações que levaram estes estudantes a virem até o Brasil tendo como horizonte a contribuição com seus países de origem, o que impacta inclusive na escolha do curso em primeiro lugar (Silva, 2015; Subuhana, 2009; Carvalho, 2016).

Passaremos agora à apresentação de dois pontos que aparecem com frequência, embora não sejam consensuais na literatura.

Para além do que já foi citado até o momento, a questão racial em termos de discriminação, estereótipo, preconceito racial e racismo aparece em todos os relatos destes e destas estudantes. No entanto, enquanto alguns autores e autoras apresentam este relato como uma breve descrição, outros optam por aprofundar-se e contextualizar teoricamente tal problemática. Nesta seara, localiza-se a formação social histórica brasileira de forma racializada a partir de lentes teóricas como a própria imigração (Carvalho, 2016; Có, 2011;), o racismo científico (Filgueira, 2014), a cultura e outros referenciais (Desiderio, 2006; Mourão, 2013; Mungoi, 2004; Pedro, 2000; Souza, 2014). Destacam-se ainda os estudos que apresentam contextualização histórica sobre a ideologia do branqueamento e a questão da raça e mestiçagem brasileira (Hirsch, 2007), a reflexão da raça como categoria sociológica analítica (Cabral, 2015) e o debate localizado a partir dos relatos (Gomes, 2002; Assunção, 2015).

O último bloco que a revisão temática denunciou foram as discussões em torno da questão de gênero.

Pensar em termos das diferenças de gênero no processo migratório ou diaspórico implica dizer que, ainda que seja um fenômeno majoritariamente masculino, são urgentes as leituras que tenham outro foco. Nesse sentido, uma virada proposta na articulação de teorias feministas com a migração é que ela pode ser pensada, planejada e gestada em um lugar de autonomia para as mulheres (Mayorga, 2011; Ferreira, 2017). Temos ainda a necessidade de uma mudança nos aportes teóricos e metodológicos que tendem a ver as mulheres como agentes secundárias dos processos migratórios, vistas como "acompanhantes, dependentes ou simplesmente invisíveis nos fenômenos analisados” (Peres, 2017: p. 240).

As poucas menções sobre a situação das mulheres africanas na literatura aqui revisada estavam vinculadas às relações afetivas e ao racismo brasileiro (Mendes, 2002; Mourao, 2013; Mendonça, 2017; Pedro, 2000; Okawati, 2015; Ngomane, 2010). Temos também a reflexão de que o deslocamento de mulheres cabo-verdianas se deu um pouco mais tarde que o dos homens, apontando inclusive que são a maioria em diáspora em algumas comunidades (Alves, 2008). Aponta-se a questão do gênero como um dos critérios 
de aproximação e de criação dos círculos de amizade, além da nacionalidade, e o papel da mulher nos espaços sociais dos e das estudantes (Mungoi, 2006). E há ainda um trabalho que observa e elabora reflexões sobre o aumento da mobilidade estudantil africana de mulheres (Feijó, 2013). Em algumas situações, as mulheres que ousam questionar alguns sistemas de ocupação do espaço público se sentem incompreendidas pelos seus, ou seja, pelas pessoas de seu próprio grupo (Ferreira, 2017). As tensões entre a experiência de diáspora com fins de trabalho ou com fins de estudos atingem as mulheres de maneira muito particular (Bento, 2005).

É importante que sejam realizadas algumas considerações sobre a pouca frequência de relatos e reflexões teóricas sobre a experiência das mulheres nos trabalhos revisados sobre estudantes africanos e africanas. Esta pouca frequência diz respeito à ausência física de fato; como apontado por alguns autores revisados e pelas teorias feministas e de migração, é muito recente o deslocamento territorial de mulheres, o que pode estar relacionado às relações de desigualdade de gênero. Por outro lado, é importante considerarmos outro olhar sobre esta experiência que não pressupõe uma distinção de gênero, ou, pelo menos, não nestes termos. Esta é uma das características levantadas pelo mulherisma africana e por análises da experiência da mulher pela lente teórica da diáspora africana.

Na proposta da mulherisma africana de Nah Dove fala-se, por exemplo, do papel central da mulher na reconstrução, recuperação e criação de uma integridade cultural em torno dos valores da reciprocidade, equilíbrio, harmonia, justiça, verdade, ordem, entre outros (Dove, 1998). Também a antropóloga brasileira Luciane Rocha, em sua tese de doutorado, apresenta o argumento de que a maternidade negra é uma recriação da sociabilidade na diáspora africana a partir da escravização, através de atos criativos, estimulantes, resistentes e recuperativos contra as práticas genocidas de violência anti-negra (Rocha, 2014). Não se alcançou refletir sobre tais incidências na pesquisa de mestrado empreendida por esta autora, porém parece um caminho profícuo para pesquisas posteriores. No entanto, uma reflexão acerca das experiências das universitárias haitianas apontando para insurgências nas relações estabelecidas com o país de origem, de destino e outros aspectos começou a ser articulada (Francisco, 2019).

\section{CONSIDERAÇÕES FINAIS}

A revisão de literatura aqui apresentada demonstra a importância dos estudos já realizados para distintas áreas do conhecimento e a urgência de leituras mais localizadas e aprofundadas sobre o tema da diáspora estudantil e todos os temas adjacentes que o mesmo toca ou evoca. Gostaria de mencionar uma das adjacências a seguir.

As gerações de jovens intelectuais africanos do final do século XIX e do início do século XX foram responsáveis pela formação do pensamento de libertação que articulava as bases epistemológicas do anticolonialismo. Pensando especificamente nos países lusófonos, desde os anos de 1940, já havia migrações de jovens das colônias portuguesas para estudar em Portugal, já que nas colônias ainda não havia universidades (Silva, 2015; Mourão, 2013). Estes estudantes eram pertencentes à classe média colonial e neste con- 
texto de ausência de fomento para o ensino superior por interesse político das colônias, foi que os países africanos estabeleceram acordos internacionais em prol deste desenvolvimento. O Programa Estudantes Convênio (PEC-G) criado em 1964 se encaixou muito convenientemente nesta lógica.

No período apontado acima, este grupo de estudantes representava uma elite que, de certa forma, contribuiria para perpetuar a lógica colonial e tinha pouco interesse de que as condições estruturais se modificassem. Por outro lado, há que se pensar que no período pós Segunda Guerra Mundial, é esta mesma elite intelectual que começa a questionar de forma contundente o colonialismo e o racismo que estavam imersos, formando e participando dos movimentos de libertação nacional. Portanto, a experiência de deslocamento com fins de estudos tem crucial importância na conquista da emancipação destes países (Castelo, 2010; Mourão, 2013). Muitas pontes poderiam ser feitas com o contexto brasileiro.

Uma das reflexões que podemos chegar aqui é que estudantes que outrora se tornaram figuras importantes na libertação de seus países podem ser a inspiração para o deslocamento de estudantes de países que se encontram com problemas econômicos, políticos e sociais, se convertendo em uma vanguarda na resolução destes problemas, estando estes estudantes em seus países ou não (Bittencourt \& Ferreira, 2006). Portanto, ainda que para alguns casos a lógica de uma família privilegiada que envia seus filhos para estudar no exterior ainda permaneça, existem outras possibilidades, motivações e trajetórias nesta diáspora.

\section{REFERÊNCIAS BIBLIOGRÁFICAS}

ALVES, Maria de Fátima Carvalho. (2008). Representações Sociais e Construção da Identidade de cabo-verdianos no Rio de Janeiro: Estudantes, Imigrantes e Descendentes. Dissertação (Mestrado em Psicologia Social) - Instituto de Psicologia, Universidade do Estado do Rio de Janeiro, Rio de Janeiro - PPGPS.

AMARAL, Joana de Barros. (2013). Atravessando o Atlântico: o programa estudante convênio de graduação e a cooperação educacional brasileira. 2013. 132 f. Dissertação (Mestrado em Desenvolvimento, Sociedade e Cooperação Internacional) —Universidade de Brasília, Brasília.

ASSUNÇÃO, Mônica Pontes de. (2015). Relações cotidianas no ambiente instituído da UFPA: a experiência dos acadêmicos de países africanos. Dissertação (Mestrado em Educação) - Universidade Federal do Pará, Belém.

BAENINGER, Rosana. (2018). "Contribuições da academia para o pacto global da migração: o olhar do sul.” In: BAENINGER, Rosana et al. (Orgs.). Migrações Sul-Sul. Campinas: Nepo/Unicamp.

BATISTA, Hilton Sales. (2015). O projeto Milton Santos de acesso ao ensino superior (Promisaes) como política de assistência estudantil ao programa de estudantes-convênio de graduação (PEC-G). 152 p. Dissertação (Mestrado Profissional em Educação) - Universidade de Brasília, Brasília.

BENTO, Artur Monteiro. (2005). A Comunidade Caboverdiana no Rio de Janeiro: memória híbrida, identidade e diferença. Rio de Janeiro: PPGMSD/UNIRIO, 119 p. Dis- 
sertação (Mestrado em Memória Social e Documento) - Centro de Ciências Humanas e Sociais, Universidade Federal do Estado do Rio de Janeiro, Rio de Janeiro.

BIZON, Ana Cecília Cossi. (2013). Narrando o exame CELPE-Bras e o convênio PEC-G: a construção de territorialidade sem tempos de internacionalização. Tese de Doutorado. Universidade Estadual de Campinas, Campinas.

BRASIL. (2012). Ministério das Relações Exteriores. "Portaria n 200, de 20 de março de 2012”. Divisão de Temas Educacionais. Brasília. Recuperado em 18 de outubro de 2018 de http://www.dce.mre.gov.br/PEC/G/Bolsas/Portaria_200-2012-ATUAL.pdf.

. (2013). "Decreto no 7.948, de 12 de março de 2013". Dispõe sobre o Programa de Estudantes-Convênio de Graduação PEC-G. Brasília.

. (2017). Lei $\mathrm{n}^{\circ} 13.445$, de 24 de maio. Lei de Migração.

CABRAL, Frederico Matos Alves. (2015). Os estudantes africanos nas Instituições de Ensino Superior brasileiras: O Programa de Estudante Convênio de Graduação (PEC-G). Dissertação (Mestrado em Sociologia) - Universidade Federal do Rio Grande do Sul, Porto Alegre.

CARVALHO, S.M.R. (2016). O projeto de ser na imigração: uma perspectiva fenomenológica-existencial. Dissertação de mestrado, Programa de pós-graduação em Psicologia, Universidade de Fortaleza, Fortaleza, CE.

CASTELO, Claudia. (2010). A casa dos estudantes império: lugar de memória anticolonial. VII Congresso Ibérico de Estudos Africanos-CIEA7, ISCTE-IUL, Lisboa, 9-11th September 2010. Recuperado de: https://repositorio.iscte-iul.pt/bitstream/10071/2244/1/CIEA7 6 CASTELO $\% 20 \mathrm{~A} \% 20 \mathrm{Casa} \% 20 \mathrm{dos} \% 20$ Estudantes $\% 20 \mathrm{do} \% 20 \mathrm{Imp} \% \mathrm{C} 3 \%$ A 9 rio.pdf.

CASTRO, Alda Araújo; CABRAL NETO, Antônio. (2012). "O ensino superior: a mobilidade estudantil como estratégia de internacionalização na América Latina". Revista Lusófona de Educação, (21), 69-96. http://www.scielo.mec.pt/scielo.php?script=sci arttext\&pid=S1645-72502012000200005\&lng=pt\&tlng=pt. (Consultado em: 20/10/2020).

CÓ, J.P.P. (2011). Filhos da independência: etnografando os estudantes Bissau-guineenses do PEC-G em Fortaleza-CE e Natal-RN. Dissertação de mestrado, Programa de pós-graduação em Antropologia Social, Universidade Federal do Rio Grande do Norte, Natal, RN.

CULPI, Ludmila. (2017). "Nova lei de migrações brasileira: Inspiração no modelo da lei argentina?". Curitiba: Nepri. http://www.humanas.ufpr.br/portal/nepri/files/2012/04/Nova-lei-de-migrações-brasileira_Inspiração-no-modelo-da-lei-argentina.pdf. (Consultado em: 16/01/2019).

DESIDERIO, E.J. (2006). Migração internacional com fins de estudo: o caso dos africanos do programa estudante-convênio de graduação em três universidades públicas no Rio de Janeiro. Dissertação de Mestrado, Programa de Pós-Graduação em Estudos Populacionais e Pesquisas, Fundação Instituto Brasileiro de Geografia e Estatística, Rio de Janeiro, RJ.

DIAS, Maria Lucia de Oliveira. (2016). Avaliação do programa de estudantes convênio de graduação PEC-G: o olhar dos alunos da UNIRIO. Dissertação (Mestrado Profissional em Avaliação), Fundação Cesgranrio, Rio de Janeiro.

DJALÓ, Mamadú. (2014). Relações Sul-Sul: A Cooperação Brasil-Guiné-Bissau Na Educação Superior No Período de 1990 - 2011. 273 p. Tese (doutorado) - Universidade 
Federal de Santa Catarina, Florianópolis.

DOMENECH, Eduardo. (2015). "O controle da imigração "indesejável”: expulsão e expulsabilidade na América do Sul". Ciência e Cultura, 67(2), 25-29. Recuperado em 18 de outubro de 2018 de: https://dx.doi.org/10.21800/2317-66602015000200010

DOVE, Nah. (1998). "Mulherisma Africana: Uma teoria afrocêntrica". Jornal de Estudos Negros, Vol. 28. № 5. Maio 1998. 515-539. https://estahorareall.files.wordpress. com/2015/11/mulherisma-africana-uma-teoria-afrocecc82ntrica-nah dove.pdf. (Consultado em: 18/10/2018).

FEIJÓ, Rosemeri Nunes. (2013). A internacionalização da educação superior no Brasil: um estudo de caso de alunos estrangeiros do Programa de Pós-Graduação em Antropologia Social/UFRGS. Dissertação (Mestrado em Educação) - Faculdade de Educação, Universidade Federal do Rio Grande do Sul, Porto Alegre.

FERREIRA, Rubens da Silva. (2017). Estudantes estrangeiros no Brasil: migrações, informação e produção de diferença. 291 f. Tese (Doutorado em Ciência da Informação) - Universidade Federal do Rio de Janeiro, Rio de Janeiro.

FIGUEIREDO, Denise Miranda. (2013). Diálogos interculturais dentro de uma universidade brasileira. Tese (Doutorado em Psicologia Clínica) - Pontifícia Universidade Católica de São Paulo, São Paulo.

FILGUEIRA, Maria Goretti Medeiros. (2014). Vozes D'África Transatlântica: Trajetórias Estudantis de Cabo Verde e da Guiné-Bissau - Programa de Estudantes. Dissertação (Mestrado em Ciências da Educação) - Universidade Lusófona de Humanidades e Tecnologias, Lisboa.

FRANCISCO, C. R. (2019). Trajetórias em diáspora: a experiência de universitárias haitianas de Belo Horizonte. Dissertação (Mestrado em Psicologia) - Universidade Federal de Minas Gerais, Belo Horizonte.

FRANCISCO, Camila Rodrigues; MAYORGA, Claudia. Insurgências nas trajetórias em diáspora de universitárias haitianas em Belo Horizonte, Brasil. Gênero. v. 20, n. 2, 2020. https:// periodicos.uff.br/revistagenero/article/view/44569/25623. (Consultado em: 30/08/2020).

GILROY, Paul. (2001). O Atlântico negro: modernidade e dupla consciência. São Paulo: Ed. 34.

GOMES, José Manuel Sita. (2002). Estudantes na terra dos outros: a experiência dos universitários angolanos da Universidade Federal de Minas Gerais. Dissertação (Mestrado em Educação) - Faculdade de Educação Universidade Federal de Minas Gerais, Belo Horizonte.

HIRSCH, O.N. (2007). "Hoje eu me sinto africana”: processos de (re)construção de identidades em um grupo de estudantes cabo-verdianos no Rio de Janeiro. Dissertação de mestrado, Programa de Pós-Graduação em Ciências Sociais, Pontifícia Universidade Católica do Rio de Janeiro, Rio de Janeiro, RJ.

LANGA, Ercílio Neves Brandão. (2016). Diáspora Africana no Ceará no Século XXI: ressignificações identitárias de estudantes imigrantes. $563 \mathrm{f}$. Tese (doutorado) - Universidade Federal do Ceará, Centro de Humanidades, Programa de Pós-Graduação em Sociologia, Fortaleza.

LOURENÇO, Izaulina Videira Ramos. (2016). Filhos da África na UFRR: vivências e experiências dos estudantes PEC-G. Dissertação (Mestrado em Sociedade e Fronteiras) - Universidade Federal de Roraima, Boa Vista. 
MAYORGA, Claudia. (2011). Cruzando fronteiras: prostituição e imigração. Cadernos Pagu, (37), 323-355. https://dx.doi.org/10.1590/S0104-83332011000200014. (Consultado em: 18/10/2018).

MENDES, Chirley Ferreira. (2012). Uma vitrine do Brasil: telenovelas brasileiras entre estudantes africanos. 190 f. Dissertação (Mestrado em Antropologia Social) - Universidade de Brasília, Brasília.

MENDONÇA, Francisco Weslay Oliveira. (2017). Implicações psicossociais do preconceito e do racismo em estudantes africanos da universidade da integração internacional da lusofonia afro-brasileira. Dissertação (Mestrado em Psicologia). Universidade Federal do Ceará, Centro de Humanidades, Fortaleza - CE.

MIRANDA, Y. C. C. (2016). Projeto "Pelo Mundo": a configuração de uma política linguística em um curso de português como língua adicional para candidatos ao Programa de Estudantes-Convênio de Graduação (PEC-G). Dissertação (Mestrado em Linguística Aplicada). Universidade Federal de Minas Gerais, Faculdade de Letras. Belo Horizonte. 178 p.

MOURAO, D.E. (2013). Outros atlânticos: reconfigurações identitárias de estudantes cabo-verdianos em trânsito entre Cabo Verde, Portugal e Brasil. Programa de Pós-Graduação em Ciências Sociais, Universidade do Estado do Rio de Janeiro, Rio de Janeiro, RJ.

MUNGOI, D. M. D. C. J. (2006). “O Mito Atlântico”: relatando experiências singulares de mobilidade dos estudantes africanos em Porto Alegre no jogo de reconstrução de suas identidades étnicas. Dissertação de mestrado, Programa de pós-graduação em Antropologia Social, Universidade Federal do Rio Grande do Sul, Porto Alegre.

NGOMANE, Yara Neusa. (2010). Estudantes moçambicanos em Belo Horizonte: uma discussão sobre a construção identitária e de redes de sociabilidade. $100 \mathrm{f}$. Dissertação (Mestrado) -- Universidade Federal de São Carlos, São Carlos.

OKAWATI, J.A.A. (2015). Estudantes africanos na UFSC. (Des)encantos extramuros na jornada acadêmica. Dissertação de mestrado, Programa de pós-graduação em Antropologia Social, Universidade Federal de Santa Catarina, Florianópolis.

PEDRO, V.T. (2000). Identidades traduzidas num mundo globalizado: os estudantes africanos em Florianópolis. Dissertação de mestrado, Programa de pós-graduação em Antropologia Social, Universidade Federal de Santa Catarina, Florianópolis.

PERES, Roberta. (2017). “Imigração e gênero mulheres haitianas”. In: Baeninger, Rosana; Peres, Roberta; Fernandes, Duval; Silva, Sidney Antonio; Assis, Gláucia de Oliveira; Castro, Maria da Consolação G.; Continguiba, Marília Pimentel. (Orgs.). Imigração Haitiana no Brasil. Jundiaí, Paco Editorial. p. 639-653.

PINTO, Marialva Moog, \& LARRECHEA, Enrique Martínez. (2018). Internacionalização da educação superior: uma análise das tendências de mobilidade dos estudantes entre países do norte e do sul global. Avaliação: Revista da Avaliação da Educação Superior (Campinas), 23(3), 718-735. https://doi.org/10.1590/s1414-40772018000300009. (Consultado em: 20/10/2020)

PIRES, Thula Rafaela de Oliveira; Berner, Vanessa Oliveira Batista; França, Julia Monteath de. (2016). "Os estudantes africanos no brasil na perspectiva da teoria crítica dos direitos humanos". Quaestio Iuris, vol. 09, n . 02, Rio de Janeiro. pp. 757-787. 
ROCHA, Luciane de Oliveira. (2014). Outraged Mothering: Black Women, Racial Violence, and the Power of Emotions in Rio de Janeiro's African Diaspora. Ph.D. Anthropology, University of Texas.

SANTOS, Mariana B. (2012). Ser kinois no Brasil: Projetos e expectativas de estudantes congoleses em universidades no Rio de Janeiro. Dissertação (Mestrado em Antropologia) Universidade Federal Fluminense, Niterói.

SILVA, Anso da. (2015). Diáspora africana e educação. Dissertação (Mestrado em Políticas Públicas) - Universidade Federal do Maranhão, São Luis.

SOUSA, Alzira Dias. (2015). O Programa de Estudantes-Convênio de Graduação na Universidade Federal da Bahia: percepção dos estudantes PEC-G oriundos dos Países Africanos de Língua Oficial Portuguesa- anos 2009-2013. Dissertação (Mestrado em Estudos Interdisciplinares) - Universidade Federal da Bahia, Salvador.

SOUZA, L.F. (2014). Migração para qualificação da força de trabalho e a questão racial: estudantes africanos/as lusófono/as negros/as em universidades goianas. Tese de doutorado, Programa de Pós-graduação em Geografia Humana, Universidade de São Paulo, São Paulo, SP.

SUBUHANA, Carlos. (2009). "A experiência sociocultural de universitários da África Lusófona no Brasil: entremeando histórias”. Pro-Posições, 20(1), 103-126. Recuperado em 23 de novembro de 2017 de https://dx.doi.org/10.1590/S0103-73072009000100007.

TAMBIAH, Stanley J. (2000). "Movimientos transnacionales, diáspora y modernidades múltiples". In: Golubov, Nattie. Diáspora: reflexiones teóricas. Universidad Nacional Autónoma De México: México, D.F, 2011. p. 127-148.

TCHAM, Ismael. (2012). A África fora de casa: sociabilidade, trânsito e conexões entre os estudantes africanos no Brasil. 99 f. Dissertação (Mestrado em Antropologia) - Universidade Federal de Pernambuco, CFCH. Programa de Pós-Graduação em Antropologia, Recife.

Recebido em 27/10/2020 - Aprovado em 29/10/2020 